\title{
THE EFFECT OF ANTIMONY DIMERCAPTO-SUCCINATE ON THE ELECTROCARDIOGRAM
}

\author{
BY \\ A. DAVIS \\ From the Bilharzia Research Group, Medical Research Council, Nairobi, Kenya
}

Received January 1, 1961

Antimony dimercapto-succinate (TWSb) has been introduced in recent years for the treatment of the three main types of human bilharziasis. Preliminary pharmacological studies indicated reduced toxicity compared with the older antimonials (Friedheim et al., 1954). In view of the known cardiographic changes following the use of other trivalent antimonials, the effects of this new preparation were studied.

Methods. The electrocardiograms were recorded during a small clinical trial previously reported (Davis, 1961). Nineteen male African children or adolescents, aged 11-20 years, weighing 26-57 kg., and all suffering from Schistosoma mansoni, Schistosoma hamatobium, or double infections were treated. Total dosage ranged from $1.0 \mathrm{~g}$. in five days to $2.0 \mathrm{~g}$. in three days. The drug was given intravenously in divided doses daily. Electrocardiograms were obtained on a direct writing machine, employing the standard leads I, II, III, augmented unipolar limb leads, aVR, aVL, aVF (Goldberger, 1953), and chest leads V1-V6 (American Heart Association, 1938). Twelve lead recordings were made before treatment, daily during it, and for the first two or three days after. Follow-up electrocardiograms were recorded in one case at 18 days, in twelve at between 28 and 33 days, and in five at 13 and 54 days after completion of treatment: one patient did not attend for follow up. All recordings were taken with the subject lying comfortably on a couch, the head of which was raised $30^{\circ}$ from the horizontal. None of the patients had physical signs of cardiovascular disease, none had received any medication during the previous four weeks, and none had had antimonial treatment. Continuous cardiograms showed no abnormality during or immediately after injection of the drug.

The electrocardiographic features analysed were the heart rate and rhythm, position, rotation, axis deviation, and the presence or absence of right or left ventricular hypertrophy. The amplitude, duration, and any special features of the $\mathrm{P}$ wave, QRS complex, RS-T segment, and T wave in all leads were recorded. The maximal amplitude of $\mathbf{R}$ in lead II in all graphs, of $\mathbf{R}$ in VL in horizontal hearts and of $R$ in VF in vertical hearts was measured. The $\mathbf{P}-\mathbf{R}$ interval was noted and the $\mathbf{Q T} \mathrm{T}_{\mathrm{c}}$ calculated. Standardization was normal $(1 \mathrm{mv} .=10 \mathrm{~mm}$. deflection). Criteria of normality were rate, rhythm, position, rotation $\mathrm{P}-\mathrm{R}$ interval, characteristics of $P$ wave, QRS complex, RS-T segment, T wave, and amplitude of $R$ in leads II, VL, and VF (Goldberger, 1953); axis deviation (nomogram of Carter et al., 1919); criteria of right ventricular hypertrophy

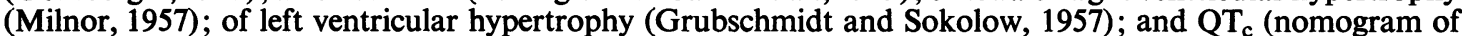
Kissin et al., 1948).

\section{RESULTS}

Before treatment 15 of 19 electrocardiograms showed iso-electric or inverted $\mathrm{T}$ waves in at least one lead. All 15 showed $\mathrm{T}$ wave inversion in one or more of the right unipolar præcordial leads, extending across to V4 in 3 cases, and 8, in addition, had various combinations of inversion of the $\mathrm{T}$ wave in other leads.

Changes were observed during treatment in the $\mathrm{T}$ waves and $\mathrm{QT}_{\mathrm{c}}$ intervals. Other analyses remained within normal limits. 
Changes in the $T$ Wave. All patients showed inverted $\mathrm{T}$ waves in one or more leads. Those who had iso-electric or inverted $\mathrm{T}$ waves before treatment showed the onset of frank inversion or an increase in the amplitude of inversion. Inversion commenced at different times during treatment, bore no relation to the amount of antimony administered, but was of maximal amplitude on the last day of treatment or during the first three days after treatment. Inversion was maximal in extent and amplitude in the right unipolar præcordial leads and the common pattern was one of progressive inversion from right to left across the chest leads. Four of 19 patients showed inversion of the $T$ wave from V1-V6 during treatment (Fig. 1). T wave inversion in the standard and augmented
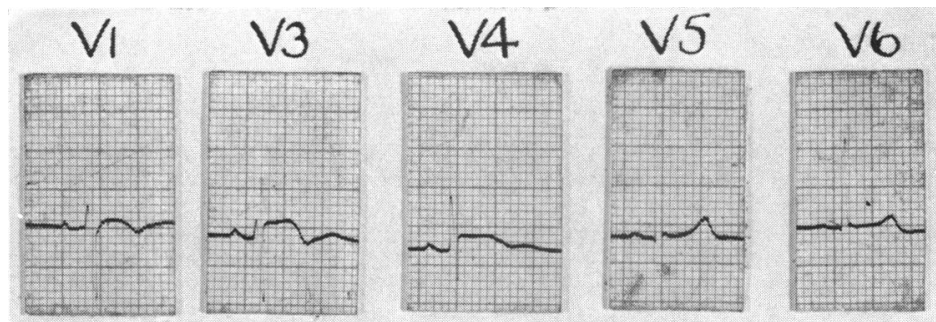

$10 \cdot 11 \cdot 59$
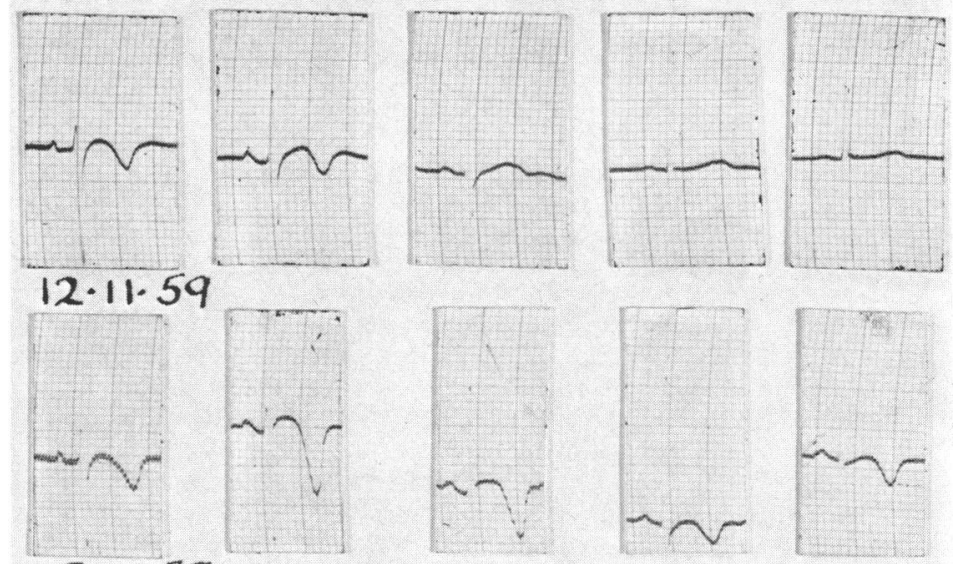

\section{$15 \cdot 11 \cdot 59$}
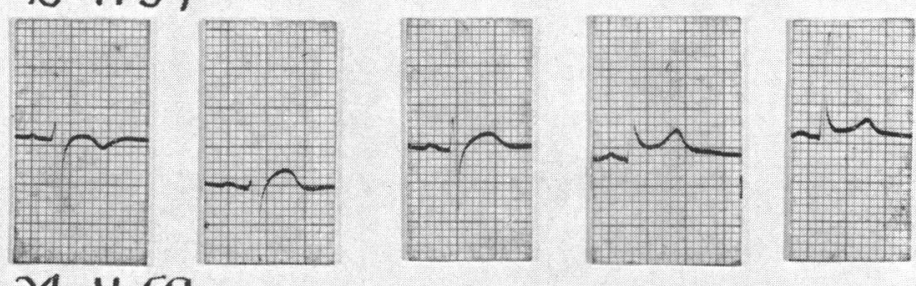

FIG. 1.-Electrocardiograms from a patient given a total dose of $1.5 \mathrm{~g}$. TWSb i.v. in 5 days. Recorded on the first and third days of treatment and on the first and tenth days after treatment. Showing inversion of the T wave progressing from right to left, with subsequent reversion.

unipolar extremity leads was much less common. There was no relation between total dosage or dose in $\mathrm{mg} . / \mathrm{kg}$. and the extent or amplitude of $\mathrm{T}$ wave inversion. However, in relation to a specific dose, inversion was greater in the right unipolar præcordial leads in those who had inverted $T$ waves at that site before treatment. Although elevation of the RS-T segment was common, such elevation 
did not exceed the normal limits as stated by Goldberger (1953), and changes in the segment were therefore regarded as being confined to the $T$ wave.

Follow-up electrocardiograms showed no abnormality in 1 case at 18 days, persistent abnormality in 7 of 12 cases at between 28 and 33 days, and in 2 of 5 cases at 54 days after treatment. This abnormality consisted of either persistent inversion of the $\mathrm{T}$ wave in the right unipolar præcordial leads or failure to regain their amplitude before treatment. In one case T in lead aVL remained inverted.

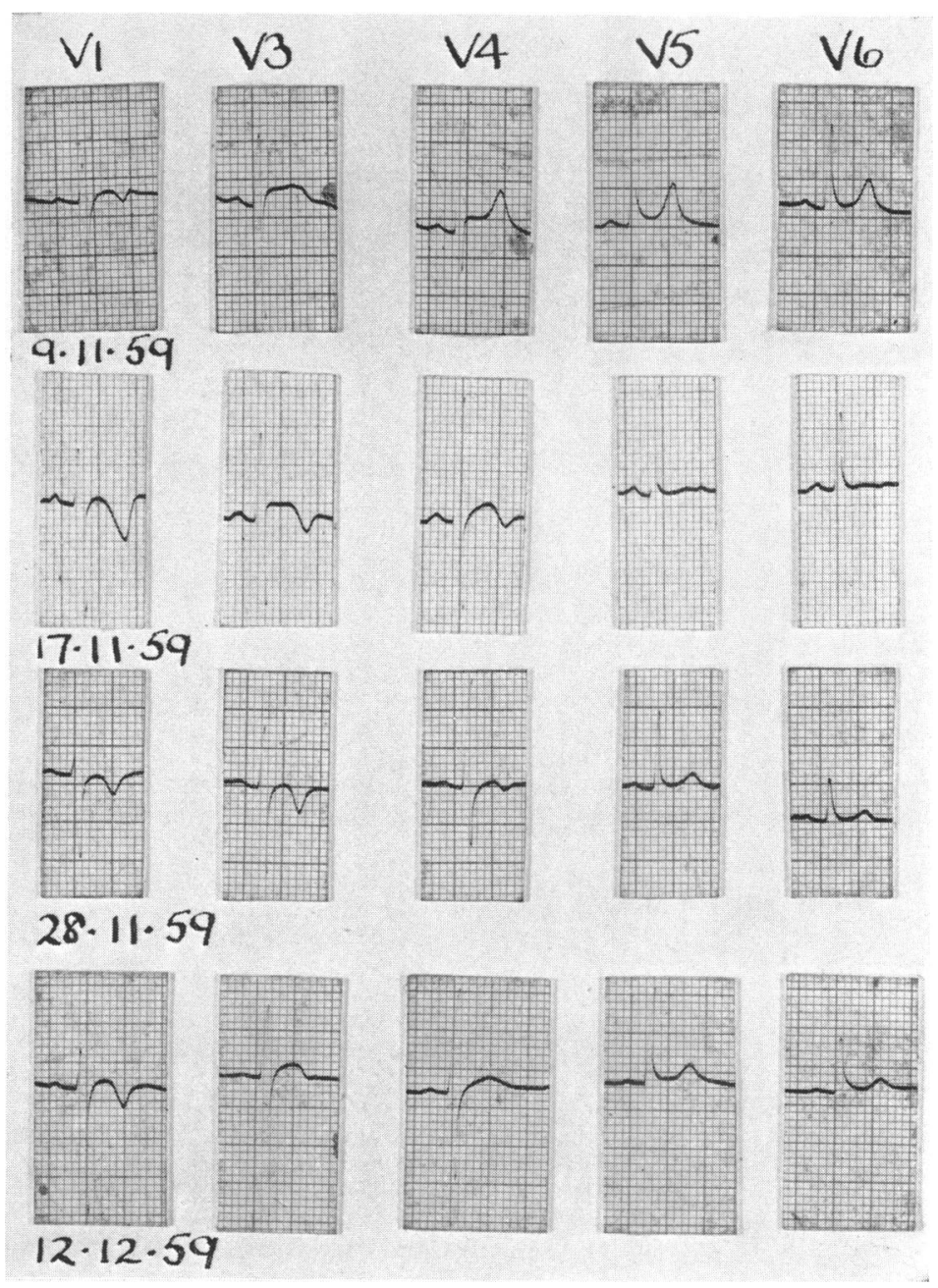

FIG. 2.-Electrocardiograms from a patient given a total dose of $1.0 \mathrm{~g}$. TWSb i.v. in 5 days. Recorded before treatment, and on the $3 \mathrm{rd}, 14 \mathrm{th}$, and 28th days after starting treatment.

Changes in the $Q T_{c}$ Interval. Prolongation of the $\mathrm{QT}_{\mathrm{c}}$ was noted in 9 out of 19 series of recordings. This appeared on the last day of treatment or during the first three days after treatment. It was transitory, lasting about two days before reverting to normal. 

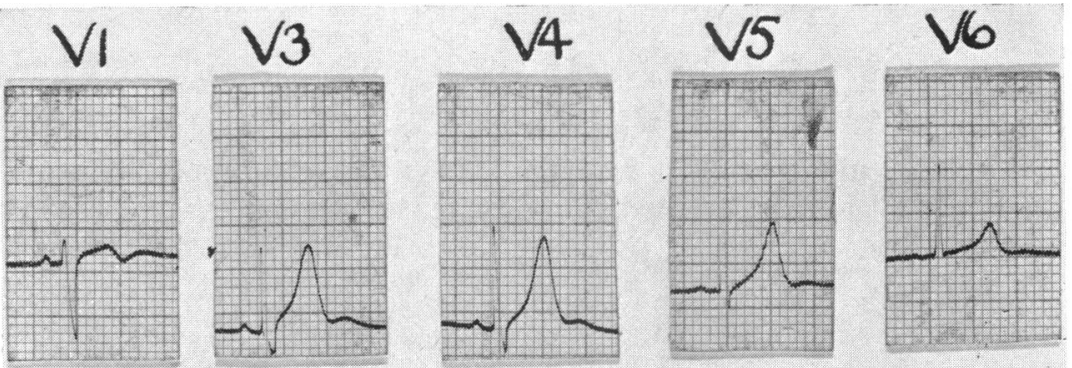

\section{$5 \cdot 12 \cdot 59$}
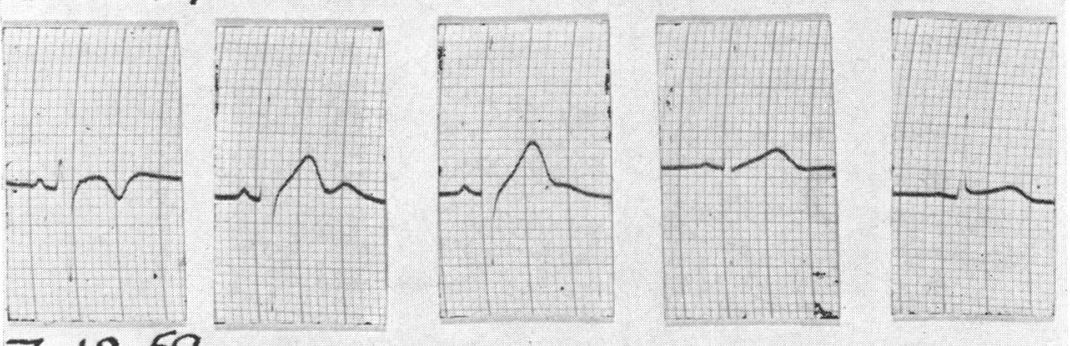

\section{$7 \cdot 12 \cdot 59$}
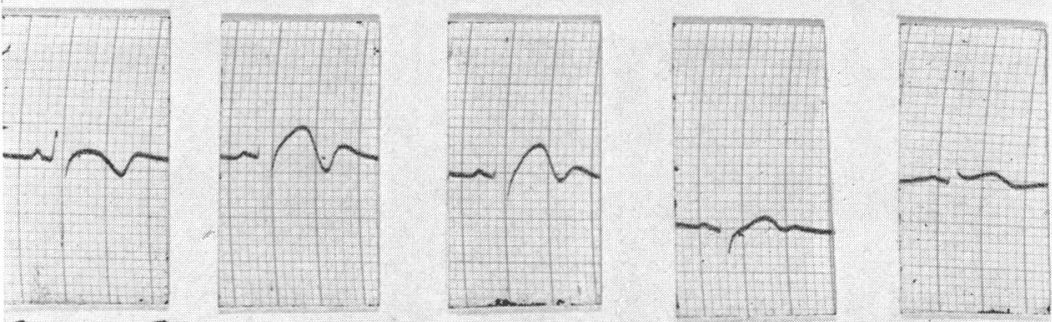

$9 \cdot 12 \cdot 59$

FIG. 3.-Electrocardiograms from a patient treated with a total dose of $1.6 \mathrm{~g}$. TWSb i.v. in 4 days. Recorded before treatment, and on the second and fourth days of treatment.

\section{DISCUSSION}

The effect of different preparations of trivalent antimony on the human electrocardiogram has been well documented, usually in studies on bilharziasis (Mainzer and Krause, 1940; Schroeder et al., 1946; Tarr, 1947; Rowland, 1956; T'ao, 1957; O'Brien, 1959; Honey 1960; and others). The most constantly observed changes were reduction in amplitude or inversion of the $T$ wave and prolongation of the QT interval. These changes were transitory and disappeared in 4-6 weeks.

Previous studies on TWSb have not emphasized the electrocardiographic findings. Friedheim et al. (1954) performed serial records on 10 patients, of whom 6 were treated by the intramuscular route and 4 intravenously. Reversible changes in the amplitude of the $T$ wave were noted. It was concluded that even massive doses of TWSb had no significant cardiovascular effect. Schneider (1956) disagreed and quoted two cases treated with the drug in which cardiographic changes were seen comparable with those of other antimonials. Salem et al. (1957) recorded cardiograms on 12 patients before and after treatment, 4 of whom showed $\mathrm{T}$ wave depression disappearing in two to three weeks.

It is not proposed to discuss the $T$ wave inversion before treatment except to remark that it occurs among Africans of all ages (Brink, 1951; Powell, 1959; and Turner, 1959), and various 
theories have been advanced for its causation. Præcordial $\mathrm{T}$ wave inversion in children is a normal finding (Goldberger, 1953). Uncomplicated Schistosoma mansoni or Schistosoma hamatobium infections do not cause electrocardiographic changes, and thus there can be no doubt that the changes in the present group were due to the drug. These changes did not differ from those previously described with the use of other therapeutic trivalent antimonials.

The exact cause of such changes is unknown. Mainzer and Krause (1940) thought that the T wave changes were due to the toxic action of antimony on the heart muscle. Tarr (1947) considered they represented alterations in the electrical activity of the ventricle probably due to a temporary deposition of antimony in the myocardium. Magalhães and Dias (1944) suggested that dilatation of the capillaries of the coronary system with resultant diminution in the effective cardiac circulation was responsible. T'ao and Huang (1952), quoted by Huang et al. (1960), initiated the idea that antimony accumulation in the myocardium caused suppression of intracellular enzymic activity with impaired cellular respiration causing a "functional disturbance" of the heart. Huang et al. (1958) proposed a nervous reflex mechanism mediated through the vagus as a causal factor in the dysrhythmic complications of antimonial therapy. However, they did not deny the local effects of antimony on the myocardium and concluded that both mechanisms played a part in their pathogenesis.

Disturbances of the sympathetic nervous system or of myocardial electrolyte balance have also been invoked as ætiological agents. Brady et al. (1945) demonstrated deposition of antimony in the thyroid glands of dogs after injection of radioactive tartar emetic, and minute amounts of the metal were noted in the atria. In other species, Franz (1937) and Bradley and Fredrick (1941) found pathological changes in the myocardium after antimonials. The work of Bartter et al. (1947) suggested that while injected antimony was rapidly cleared from the blood stream and a proportion quickly excreted, the residuum was dealt with much more slowly. Thus, circumstantial evidence has implied temporary myocardial damage from accumulation of toxic trivalent antimony as the cause of electrocardiographic abnormalities.

In the present group of cases, the time of occurrence of maximal electrocardiographic change and the fact that the changes were largely reversible over a period of weeks, which roughly paralleled the excretion rate of residual antimony, indirectly supported this concept. Hence it can be stated that cardiographic changes occur after all types of therapeutic trivalent antimonial drugs and after widely varying amounts. Naturally, some preparations produce a greater number of changes than others, probably depending on the ease with which antimony is liberated from different compounds (Tarr, 1947). It should be noted in passing that cardiographic changes following pentavalent antimonials are much less, these compounds being less toxic than the trivalent ones.

The reason for the predominance of changes in the right unipolar præcordial leads was unknown. Brink (1951) produced inverted $T$ waves at this site in healthy people by cooling the chest wall, and Brink and Goodwin (1952) showed that small superficial areas of muscle damage in the anterior myocardial wall produced cardiographic effects comparable with those of the cooling proceedure; they suggested that slight muscle damage may result in extensive $T$ wave changes, and that when these were the only cardiographic evidence of muscle damage, the lesion was probably not large and only superficial. Although changes in the $\mathrm{T}$ wave and Q-T interval are often non-specific, in the present context they were presumably compatible with temporary superficial myocardial damage. The prolonged $\mathrm{QT}_{\mathrm{c}}$ occurred with a normal QRS and represented an increase in the time taken for the stimulated ventricles to return to normal.

Agreement has not been reached on the clinical significance of the cardiographic changes after antimonials, one school regarding them of small import but another viewing their appearance with suspicion. Although their significance may perhaps be minimized in relatively healthy Europeans, many indigenous inhabitants of the tropics suffer from multiple pathological conditions, and in these patients the changes should not be dismissed lightly. Sudden death (Khalil, 1928), acute circulatory failure (Talaat and Shoaib, 1947), ventricular dysrhythmias, and Stokes-Adams attacks (T'ao, 1957; and O'Brien, 1959) have all occurred during antimony treatment, and bore little relation to preceding electrocardiographic change. The exact cause of death was probably ventricular 
dysrhythmia and the relationship to antimony treatment was well established. For many years exercise has been known to be a precipitating factor in such cases (Khalil, 1928). In the present series patients were confined to bed for two hours following injection, after which they were allowed to take part in light ward activities. One patient showed transient ventricular extrasystoles and another had a syncopal attack: examination ten minutes after the attack showed no abnormality.

Thus, although antimony dimercapto-succinate may be less toxic than older antimonials, similar electrocardiographic changes occurred, whether patients were treated intramuscularly (Friedheim et al., 1954) or intravenously. These changes were maximal at the end of the period of treatment and probably represented temporary superficial myocardial damage. Advice given to children or adolescents to avoid exercise may not be obeyed, and young patients should not be discharged prematurely from hospital or out-patient surveillance. As it was impossible to predict which patients would show changes on treatment or at what dosage changes would appear, electrocardiographic control should be exercised when possible. This is a counsel of perfection in tropical practice where facilities are commonly lacking, and thus the safeguards introduced for use with other antimonials should be applied, i.e. avoidance of intensive treatment in underweight or malnourished patients, avoidance of antimonials in the presence of clinical heart disease, hepatic disease, and renal disease, and a six-weeks interval between courses of treatment. It was encouraging to note that hard physical labour after intramuscular courses of TWSb appeared to have no deleterious effects (Friedheim, 1960).

\section{SUMMARY}

The effect of antimony dimercapto-succinate on the electrocardiogram of African children and adolescents was investigated. The changes that were found resembled those caused by other antimonial drugs. The importance of damage to the heart during antimony treatment is discussed.

I wish to thank Dr. P. E. C. Manson Bahr for provision of facilities, and Dr. E. A. H. Friedheim for supply of the drug.

\section{REFERENCES}

American Heart Association (1938). Amer. Heart J., 15, 235.

Bartter, F. C., Cowie, D. B., Most, H., Ness, A. T., and Forbush, S. (1947). Amer. J. trop. Med., 27, 403.

Bradley, W. R., and Fredrick, W. G. (1941). Indust. Med., Indust. Hyg. Sect., 2, 15.

Brady, F. J., Lawton, A. H., Cowie, D. B., Andrews, H. L., Ness, A. T., and Ogden, G. E. (1945). Amer. J. trop. Med., 25, 103.

Brink, A. J. (1951). S. Afr. J. clin. Sci., 2, 288.

and Goodwin, J. F. (1952). Brit. Heart J., 14, 331.

Carter, E., Richter, C. P., and Greene, C. H. (1919). Bull. Johns Hopk. Hosp., 30, 162.

Davis, A. (1961). E. Afr. med. J. (in press).

Franz, G. (1937). Arch. exper. Path. Pharmakol., 186, 661.

Friedheim, E. A. H. (1960). Personal communication.

- da Silva, J. R., and Martins, A. V. (1954). Amer. J. trop. Med. Hyg., 3, 714.

Goldberger, E. (1953). Unipolar Lead Electrocardiography and Vectorcardiography. 3rd. ed., Henry Kimpton, London.

Grubschmidt, H. A., and Sokolow, M. (1957). Amer. Heart J., 54, 689.

Honey, M. (1960). Brit. Heart J., 22, 601

Huang, M. H., Chiang, S. C., P'an, J. S., Yü, K. J., Lu, C. W., Hsü, C. Y., and Kao, W. S. (1958). Chin. med.J., 76, 103.

Khalil, M. (1928). J. Egypt. med. Ass., 11, 97.

Kissin, M., Schwarzchild, M. M., and Babst, H. (1948). Amer. Heart J., 35, 990.

Magalhães, B. F., and Dias, C. B. (1944). Mem. Inst. Osw. Cruz., 41, 363.

Mainzer, F., and Krause, M. (1940). Trans. R. Soc. trop. Med. Hyg., 33, 405.

Milnor, W. R. (1957). Circulation, 16, 348.

O'Brien, W. (1959). Trans. R. Soc. trop. Med. Hyg., 53, 482.

Powell, S. J. (1959). Brit. Heart J., 21, 263.

Rowland, H. A. K. (1956). Trans. R. Soc. trop. Med. Hyg., 50, 565.

Salem, H. H., Friedheim, E. A. H., and El Sherif, A. F. (1957). J. Egypt. publ. Hlth. Ass., $32,313$.

Schneider, J. (1956). Bull. Soc. Path. exot., 49, 1220.

Schroeder, E. F., Rose, F. A., and Most, H. (1946). Amer. J. med. Sci., 212, 697.

Talaat, S. M., and Shoaib, S. (1947). J. R. Egypt med. Ass., 30, 598.

T'ao, S. C. (1957). Chin. med. J., 75, 365.

and Huang, S. C. (1952). Nat. med. J. China (in Chinese)., 38, 661., quoted by Huang, M. H., Chiang, S. C., Yü, K. J., Lu, C. W., and Hsü, C. Y. (1960). Chin. med. J., 80, 319.

Tarr, L. (1947). Ann. intern. Med., 27, 970.

Turner, P. P. (1959). E. Afr. med. J., 36, 555. 